\title{
ADAPTABILITY INDEX IN Q3 2016: ALL-TIME HIGH FOR MONITORING YEARS ${ }^{1}$ \\ S.Tsukhlo
}

Adaptability Index of Russian industry ("normal" responses) posted an unexpected result in Q3 2016 (even for us who have been working with unusual for economists estimates made by enterprises of the current situation along the scale above normal-normal-below normal). It hit an all-time maximum for the entire 23 years of its calculation ${ }^{2}$.

In Q3 2016, the Adaptability Index of Russian industry hit 74 points (previously it posted not more than 72 points). According to the Index it turns out that at present Russian industry assesses the situation in the best possible way. Because the Index dynamics measured over all previous years coincide with intuitive assessment of even moderate set of data of the official industrial statistics (not to speak of a more complete system of indicators of the IEP's survey statistics) then we may consider the latest Index value as a correct estimate of the situation in Russian industry. Furthermore, it exceeds the previous value merely by 2 p.p., in other words

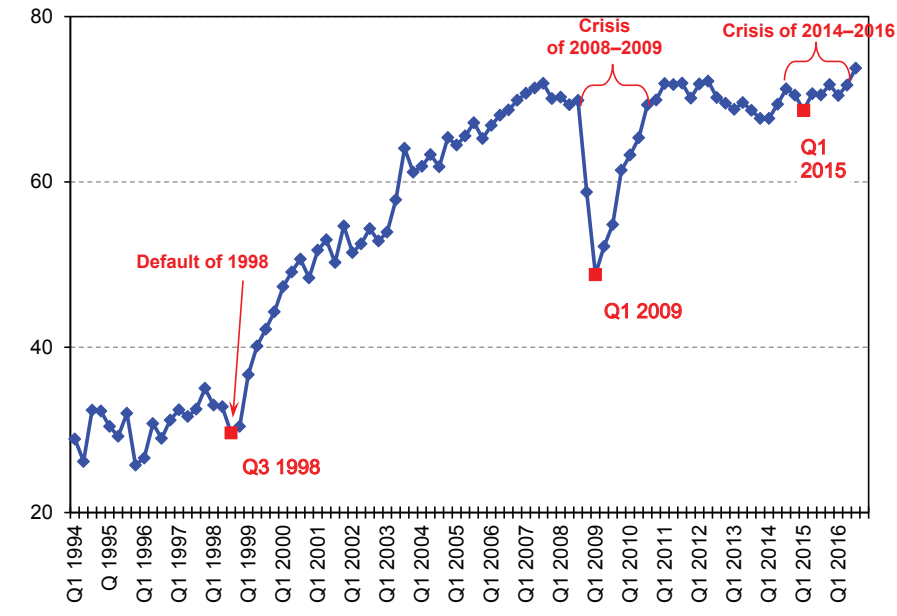

Fig. 1. Adaptability Index (normal) of industry, 1994-2016, $\%$ (share of enterprises estimating their indicators as "normal") is not an outlaying case.

It should be noted that from end-2010 our indicator has being demonstrating a very high stability by changing not more than 2 p.p. (on either side) against the previous period. Even in Q1 2015 in comparison with the previous period, the Index "crashed" barely by 1.8 points. Moreover, this value so far remains the most significant negative change of the indicator during the course of the crisis. Although both the authorities and experts were getting ready for the downturns of the 2008-2009 pattern. Russian industry found it hard during that crisis. In the end of 2008, the Adaptability Index shed 11 p.p., at the beginning of 2009 - another 10 p.p. In order to recover the Index to its pre-crisis values businesses and authorities required six quarters. In the course of the current slow-rolling crisis, the adaptability Index has not lost more than 2 p.p. in a period of a quarter, but according to the available for

1 Business surveys of managers of industrial enterprises have been conducted by the Gaidar Institute using a European harmonized method in monthly cycles since September 1992, covering the entire territory of the Russian Federation. The panel size is about 1,100 enterprises employing over $15 \%$ of industrial employees. The panel is shifted towards large enterprises for each of the segregated sub-industries. The ratio of returned questionnaires is $65-70 \%$.

2 This paper was originally published in Online Monitoring of Russia's Economic Outlook No.14(32). 
the begging of September 2016 estimates has hit all-time maximum. Notably due to nearly all its basic indicators.

\section{Estimates of employment and industrial capacity}

The number of employed has become single exception in the estimates made by businesses. Normal (sufficient) supply of labor for Russian industry according to this indicator decreased in Q3 2016 by 5 p.p. to 75\%. Thus, three fourth of Russian industry, according to our estimates, after all have sufficient number of workers for maintaining the current output volume and its possible changes. During previous crises, this indicator fell to 51\% (1996) and to $59 \%$ (2009). In other words, it is still far from its previous crisis values. In the course of the current crisis, the indicator decreased to $72 \%$ and moved up to $80 \%$. The latest value has become its all-time maximum for the entire period (1996-2016) of monitoring Russian industry's supply of labor.

Irregularity of the current crisis is evidenced by the official statistics of unemployment, which is contrary to the crisis one. This naturally reassures authorities but concerns businesses. Businesses in case of onset of more or less sustainable industrial growth simply will not be able to find worker on the labor market.

In such circumstances industry is very rarely provides responses "more than sufficient" while estimating the headcount: not more than $12 \%$ during the current crisis. In Q3 2016, the share of such responses fell to 9\% (five-year minimum). Businesses less often discharge employees than cut wages, transfer to part-time employment, or send on leave without pay. In the course of the current crisis had to take very good care of qualified workers, whose numbers are falling due to inexorable demographic processes and their replenishment from the destroyed system of vocational education is catastrophically insufficient.

Industry rather differently appraises available (assembled and installed) industrial capacity. In Q3 2016, sufficient capacity, measured as "normal", has gone up to $76 \%$ and formally is equal to normal sufficiency of labor. Latest estimates of capacity have nearly hit all-time high: the best result (78\%) was obtained in Q2 2011, when industry was about to recover after the 20082009 crisis. However, since Q3 2008 among other responses ("more than sufficient" and "less than sufficient") responses "more than sufficient" always dominate. In other words, industry during eight years has been carrying a great deal of extra capacity, which in Q1 2009 went up by 33 p.p. and logically hit maximum (+39 p.p.). However, in Q1 2015, balance of these responses fell in comparison with the previous quarter. Industry failed to detect in January 2015 symptoms of the outset of output downturn and avoided a review of capacity estimates.

\section{Stock of finished products}

Russian industry estimates stock of finished products as more "normal" with each passing "crisis" quarter. Estimates of stock of finished products for the first two months of Q3 2016 have reached normal level, which was never registered during the period of 1992-2016. In July-August 2016, 78\% of Russian industrial enterprises were completely satisfied with their stock of finished products.

Estimates of stock of finished products obtained for five crisis quarters demonstrate nearly peak level of normality in the range of $77-80 \%$. The all- 
time record (81\%) of the indicator was registered at the beginning of 2012, but turned out to be unstable. Furthermore, one should bear in mind that Russian industry never estimated its stock during 2014-2016 as crisis one. In Q1 2015, the share of normal estimates (both finished products and raw materials) in no way changed compared to estimates for Q4 2014 and the result of Q2 2015 is no different from the estimates of the previous quarter.

\section{Estimates of demand}

Estimates of the current volumes of demand moved up in Q3 2016 hitting the pre-crisis maximum of 55\% (the same result was received in Q3 2015). Thus, more than half of Russian industrial enterprises are satisfied with the sales of their products. The crisis minimum of this indicator was obtained anything but at the turn of 2015 but in Q1 2016 when industry falling for constant assurances about imminent economic growth never managed to reveal it and gave up on demand potential. This took the form of misunderstanding of the current economic situation and its prospects down to $50 \%$. Starting with Q2 2016, the level of misunderstanding has fallen to ordinary 36\% (in Q3 - to 33\%) and satisfaction with sales has moved up first to $53 \%$ and then to $55 \%$. Industry apparently has come to terms with the fact that it is no good to expect growth and was content with very little.

\section{Estimates of financial and economic state}

Russian industry measures its financial and economic state as predominantly good. In Q3 2016, 82\% of enterprises remain in good or satisfactory state (up 2 p.p. against Q2). During the current crisis, the minimum of this indicator hit 78\% (Q1 2015). During the previous crisis of 2008-2009, the share of "normal" responses regarding financial and economic state moved down to $56 \%$ and in prior to default period did not exceed $30 \%$. 